\title{
Explaining time variation in geographic price dispersion *
}

\author{
Dakshina G. De Silva ${ }^{\dagger}$ \\ Inkoo Lee \\ Soon-Chul Lee ${ }^{\S}$
}

February 14, 2019

\begin{abstract}
The pattern of price dispersion significantly varies over time and across locations. Using a detailed dataset with product-level retail prices, we examine the role of time-varying factors in shaping the time variation of price dispersion. We find that price dispersion variation in an integrated region is mainly driven by oil prices, while the variation in a segmented region is attributed to dispersion in real income. We also find that dispersion in value-added tax rates explains a significant portion of price dispersion fluctuations in both geographic dimensions. This paper offers new evindence on the trade-off that exists for the role of time-varying factors as contributors to price dispersion variation by highlighting their relative importance across different dimensions of economic geography.
\end{abstract}

Keywords: Price dispersion; Time variation; Oil prices; Income dispersion; VAT rates dispersion JEL classification: E31, F31

\footnotetext{
* We would like to thank David Peel, Rachel Pownall, and Giorgio Motta for their valuable comments.

${ }^{\dagger}$ Department of Economics, Lancaster University, Lancaster, LA1 4YX, UK. Email: d.desilva@lancaster.ac.uk

*Corresponding author: College of Economics and International Commerce, Soongsil University,369 Sangdo-Ro, Dongjak-Gu, Seoul 06978, South Korea.

$\S$ Busan University of Foreign Studies, Busan, South Korea.
} 


\section{Introduction}

Most empirical work on purchasing power parity has examined the time series distribution of international relative prices using price index numbers. For example, among others, Lothian and Taylor (1996), Cuddington and Liang (2000), Lothian and Taylor (2000), and Murray and Papell (2002) use long horizon data to test for the unit root hypothesis in real exchange rates. Recent developments in micro price data have motivated an empirical investigation of what factors determine whether deviations from the law of one price (LOP) will be large or small. For example, Crucini et al. (2005) use absolute price data to demonstrate the effect of tradeability and non-traded inputs on deviations from the LOP among European Union (EU) countries. Rogers (2007) and Parsley and Wei (2008) use retail price data to examine the effect of monetary unions, finding that most of the decline in European price dispersion occurs prior to the introduction of the euro. Gopinath et al. (2011) use retail prices in the United States (US) and Canada and show that retail prices do not respond to changes in wholesale costs in neighboring stores located across the border. Glushenkova and Zachariadis (2016) compare the explanatory power of tradeability and non-traded inputs before and after the adoption of the euro to study the evolution of European price dispersion. ${ }^{1}$

Focusing on international price dynamics, Crucini and Shintani (2008), Klenow and Malin (2010), Crucini et al. (2010), Burstein and Jaimovich (2012), and Andrade and Zachariadis (2016) use product-level price data to study time-series persistence and volatility in real exchange rates. Sarno at el. (2004), in particular, use goods data to find strong evidence of non-linear mean

\footnotetext{
${ }^{1}$ Price dispersion is defined as the cross-sectional variation in relative prices, often viewed as a measure of price deviations. At the aggregate level, greater price dispersion implies larger deviations from the purchasing power parity (i.e., larger absolute values of the real exchange rates). At the disaggregate level, greater price dispersion implies larger deviations from the law of one price (i.e., larger absolute values of the relative prices of individual
} 
reversion in the LOP deviations, suggesting the presence of transaction costs across a broad range of goods and countries. A major explanation for the failure of the LOP proposed in these studies is that retail markets are segmented by goods characteristics and geographic factors.

While successful in assessing the cross-sectional variation in the LOP deviations, this approach cannot explain heterogeneous time variation of LOP deviations - specifically, why price dispersion exhibits different time patterns across location groupings. One can easily observe that trends in price dispersion are remarkably different across the locations under examination. Since the early 1990s, geographic price dispersion has declined internationally, but this trend is significantly interrupted as we move from a less-integrated to a more-integrated group and is even reversed within a country. This implies that, in addition to the usual set of time-invariant regressors such as goods characteristics and geographic factors, time-varying factors that are either common or specific to locations are at work, motivating an investigation of their role in shaping price dispersion fluctuations.

A notable exception is Bergin and Glick (2007), who claim that a general U-shaped pattern in price dispersion between 1990 and 2005 coincides well with oil price fluctuations. They conclude that time variation is difficult to explain in terms of the standard gravity equation variables as these tend not to vary much over time, emphasizing the role of oil-related transportation costs as an important driver of international price dispersion. In the same spirit as their work, we focus on the role of time-varying factors in shaping price dispersion fluctuations using a novel dataset of retail prices.

Our analysis differs from Bergin and Glick (2007) in several ways. First, we introduce additional time-varying factors as regressors that are specific to locations. The oil price, a proxy 
for transportation costs, is expected to affect price dispersion variation by determining a timevarying band of inaction within which relative prices are bounded. Nevertheless, since the movements in oil prices are common to all regions, it is necessary to search for more apppropriate time-varying factors that are specific to locations to better capture heterogeneity in price dispersion variation. In line with theories underlying the purchasing power parity (PPP) puzzle, we additionally include income dispersion and value-added tax (VAT) rate dispersion in the regression to capture time-varying features of structural causes such as pricing-to-market and consumption tax regulations. Lothian and Taylor (2008) study the effect of income differences on the equilibrium real exchange rates - the Harrod-Balassa-Samuelson (HBS) effect. They find that the HBS effect explains a significant variation in the level of the sterling-dollar real exchange rates over the whole sample period, but the effect varies according to the time horizon considered.

Our hypothesis is that price dispersion becomes larger over time with higher oil prices, income dispersion, and VAT dispersion. We examine these predictions while pooling all available goods and years. We then show how the relative importance of these three types of time-varying factors change as we move across a two-dimensional continuum of location groupings: inter-regional and intra-regional cities. To the best of our knowledge, this is the first paper to consider this set of time-varying factors as regressors and compare their contributing power to time variation in inter-regional and intra-regional price dispersion.

Second, our analysis covers a longer time horizon in a panel regression. The U-shaped pattern of price dispersion documented in Bergin and Glick (2007) may reflect a phenomenon stemming from a relatively short time horizon. We examine this possibility by extending the ending year from 2005 to 2013.

Third, although the focus of this paper is the time dimension of price dispersion, we also 
investigate the role of goods characteristics by interacting a share of tradeable inputs with the tradeability of final goods. Of special interest is our division of goods caterories into three mutually exclusive natures: non-perishables, perishables, and services. The inclusion of interaction terms in this manner helps in understanding the explanatory power of the tradeability changes for goods requiring a low share of non-traded inputs.

Our main findings are as follows. While helpful in accounting for the time variation in world price dispersion, income dispersion does not explain a significant portion of price dispersion variation within the US. On the other hand, the role of oil prices does matter within the US, whereas world price dispersion does not significantly fluctuate in response to changes in oil prices. The VAT dispersion coincides well with price dispersion fluctuations both within and across countries. Additional analysis shows that our results are robust to alternative country groupings: OECD and EU. An important insight arising from our analysis is that the role of timevarying factors in accounting for price dispersion variation is reversed in the context of economic geography. Structural causes, such as income dispersion and VAT dispersion, matter more as we move beyond an economic geography, while transportation costs are relatively more significant as we move to the interior of this geography.

In summary, our empirical results support Bergin and Glick's (2007) conjecture on the importance of incorporating time-varying factors into the model of price dispersion. A major contribution of this paper is that it offers new evidence on the trade-off that exists for the role of time-varying factors as contributors to price dispersion variation by highlighting their relative importance across different dimensions of economic geography.

\section{Data}


The source of our micro price data is the Worldwide Cost of Living Survey collected by the Economist Intelligence Unit (EIU). ${ }^{2}$ The survey covers 300 individual retail goods and services across 140 cities in 91 countries over the period 1990-2013. The data set also includes the official nominal exchange rates needed to convert local currency prices into US dollars each year. In constructing our three-dimensional panels, we select years and locations in the following way. First, we select the sample period that begins in 1994 and ends in 2013 due to a great number of missing observations between 1990 and 1993. Second, when more than one city is available in a country, we select the city that comes first alphabetically and add cities as necessary to achieve the largest possible balanced panel for a particular good. Third, for each good, cities that contain missing observations are removed.

In terms of location groupings, we divide regions into two groupings-75 cities in World countries for international analysis and 16 cities in the US for intra-national analysis. To examine the sensitivity of benchmark results to the country groupings, we conduct regression anlysis in the robustness checks for 28 cities in OECD countries and 15 cities in the EU. ${ }^{3}$ Each group differs significantly in terms of the level of income difference and geographic proximity. Table 1 lists the cities used in the regression analysis. The number of goods for which a particular city is used in the analysis is provided in parentheses.

The survey records local prices of tightly specified items such as milk (pasteurized, 1L), aspirin (100 tablets), and Coca Cola (1 liter). The dataset also includes many service items, such as utility charges and school tuition, which would be classified as non-tradeable goods. The scope of goods and services is as comprehensive as those found in a typical consumer price

\footnotetext{
2 The data set is described in more detail at http://worldwidecostofliving.com/asp/wcol_HelpWhatIsWCOL.asp

${ }^{3}$ For the OECD and EU groups, we include 28 and 15 member countries, respectively, that became members prior
} 
index (CPI). That the prices are surveyed in absolute terms for a variety of items and locations led a number of recent studies on international price dispersion to use EIU data, including Bergin and Glick (2007), Rogers (2007), Crucini and Shintani (2008), and Andrade and Zachariadis (2016).

In conducting our analysis, we use 300 individual goods and services consisting of 219 tradeable goods (76 perishables and 143 non-perishables) and 81 service goods. These categories are used in our regression analysis to identify the tradeability of goods. The raw data are in domestic currency units so we convert all prices to US dollars at the average exchange rate prevailing for the year the price observation is recorded. ${ }^{4}$

We supplement our micro price data with data on the oil price, real income per capita, VAT rates, and a share of traded inputs. We obtain data on oil prices from the OECD Factbook, real income per capita from the World Development Indicators (WDI), the VAT rates from multiple issues of the OECD Consumption Tax Trends, and the share of traded inputs from the OECD Input-Output Database. ${ }^{5}$ The data on US metropolitan real income per capita come from the Bureau of Economic Analysis (BEA) and the retail sales taxes from the Federation of Tax

to 2000 .

${ }^{4}$ We follow the traditional method of currency conversion by using the nominal exchange rate to convert prices into US dollar in each period. One may reasonably cast doubt on this method of currency conversion because, given the sharp devaluation or revaluation often experienced by emerging economies, one can observe changes in a country's prices denominated by the US dollar even without any actual change in prices in the local currency. In light of the LOP deviation, however, this concern can be viewed as suggestive of an imperfect pass-through of the exchange rate changes to prices. Without sticky prices and market segmentation, sharp changes in exchange rates will not induce deviations from the LOP, while the positive pass-through of the exchange rate changes becomes significantly limited in the presence of these frictions. This is why the existing empirical work (Bergin and Glick (2007), Crucini and Shintani (2008), Gopinath et al. (2011), Andrade and Zachariadis (2016), etc.) uses the traditional method of currency conversion, with most of the numeraire currency being the US dollar, when examining how weak the connection actually is between exchange rates and national price. We thank the referee for pointing out this issue.

5 The website is: https://databank.worldbank.org/data/source/world-development-indicators for real income per capita, https://www.oecd-ilibrary.org/taxation/consumption-tax-trends 19990979 for VAT rates,

https://stats.oecd.org/Index.aspx?DataSetCode=IOTS for input-output data, and https://stats.oecd.org/viewhtml.aspx?datasetcode=OIWORLD\&lang=en for oil prices. 
Administrators. ${ }^{6}$ The data on real income per capita, used for robustness checks, are also available at the WDI and BEA. Because the data on the share of traded inputs are not available at the level of the individual good, we assign each good to an industry and use the industry-level measure in place of the good-specific measure. ${ }^{7}$

\section{Empirical methodology}

We define price dispersion across cities as the cross-sectional variance in the LOP deviations. Specifically, let $P_{i, j}^{k}$ be the US dollar price of good $i$ in city $j$ located in the country group $k$. For a given country group $k$, we compute the deviation of the price of each good in a particular city from its average across all cities within the country group to which the city belongs: $\bar{P}_{i j}^{k}=\log P_{i j}^{k}-\frac{1}{n} \sum_{j=1}^{n} \log P_{i j}^{k}$ where $n$ is the number of countries in the country group $k \equiv$ World, $\mathrm{US}^{8}$

Before turning to the empirical model, it is useful to demonstrate features of LOP deviations. Fig. 1 presents kernel density estimates of LOP deviations, measured as $\bar{P}_{i j}^{k}$ for the World and the US, pooling all years. For each grouping, we plot separate densities for tradeable and nontradeable goods. What the densities convey is a clear border effect. The prices within the US are

\footnotetext{
${ }^{6}$ We use retail sales taxes in place of VATs for the US.

The website is: https://apps.bea.gov/iTable/iTable.cfm?isuri=1\&reqid=70\&step=1\#isuri=1\&reqid=70\&step=1 for real income per capita, and https://www.taxadmin.org/state-tax-agencies for sales taxes. Because sales tax data are not available at the level of the individual city, we assign each city to a state and use the state-level tax rate in place of the city-level tax rate.

7 The traded input shares are computed by putting together the direct and indirect convolutions of traded input requirements. The sectors considered as traded inputs are food products, wood products, paper products, refined petroleum products, chemicals, rubber and plastic products, non-metallic mineral products, iron and steel, nonferrous metals, fabricated metal products, office and computing machinery, electrical machinery, communication equipment, precision instruments, and transportation equipment.

${ }^{8}$ This normalization avoids problems inherent in choosing an arbitrary numeraire location.
} 
clearly less dispersed than are the international prices. ${ }^{9}$ In all cases, non-tradeable goods exhibit wider price distributions than do tradeable goods. An interesting finding is that the prices of non-tradeable goods are less dispersed across US cities than are the prices of tradeable goods internationally, indicative of substantial market segmentation in the international retail market.

While useful in addressing cross-sectional variation in LOP deviations, the price distributions in Fig. 1 are not informative regarding how much price dispersion varies over time and how much of the time variation is due to time-varying factors. To determine this, we identify time-specific sources of LOP variation and compare their contributing powers across location groupings.

In our empirical work, we define the price dispersion of a good, denoted PriceDis ${ }_{i}^{k}$, as the cross-sectional standard deviation of the LOP deviations within the country group:

$$
\operatorname{PriceDis}_{i}^{k} \equiv \operatorname{std}_{j}\left(\bar{P}_{i, j}^{k} \mid i, k\right)
$$

The time series of the measure of price dispersion averaged over all goods on a year-by-year basis over 1994-2013 are shown in Fig. 2 and Fig 3. We see apparently distinct patterns in price dispersion between inter-regional and intra-regional locations. Price dispersion tends to decline in the case of the World grouping, whereas the US roughly exhibits rising time trends. Given that goods characteristics and traditional gravity variables do not vary much over time, other factors that are time-varying must be at work in the time-varying nature of price dispersion. This observation suggests the introduction of time-varying factors that are either common or

\footnotetext{
9 Although not shown here, prices are also less dispersed across EU cities than across OECD cities, reflecting that EU countries are both geographically close and economically integrated.
} 
specific to locations into a regression specification.

Our regression specification hypothesizes that time variation in price dispersion is related to oil price, income dispersion, and VAT dispersion, all of which vary over time. The baseline specification of the regression model takes the form:

$$
\begin{aligned}
\text { PriceDis }_{i, t}^{k}=\alpha_{0}^{k}+ & \alpha_{1}^{k} \ln \left(\text { Oil }_{t}\right)+\alpha_{2}^{k} \text { IncomeDis }_{t}^{k}+\alpha_{3}^{k} \text { VatDis }_{t}^{k}+\alpha_{4}^{k} \theta_{i} D_{i}^{N P} \\
& +\alpha_{5}^{k} \theta_{i} D_{i}^{P}+\varepsilon_{i, t}^{k}
\end{aligned}
$$

where $\operatorname{PriceDis}_{i, t}^{k}$ is the measure of price dispersion defined as $\operatorname{PriceDis}_{i}^{k} \equiv \operatorname{std}_{j}\left(\bar{P}_{i, j}^{k} \mid i, k\right)$, $\mathrm{Oil}_{t}$ is the nominal price of oil, $\theta_{i}$ is the share of traded inputs required to produce the good, $D_{i}^{P}$ is a good-specific dummy variable equal to one when the good is perishable, and $D_{i}^{N P}$ is a good-specific dummy variable equal to one when the good is non-perishable. IncomeDis ${ }_{t}^{k}$ denotes income dispersion and is defined as the cross-sectional standard deviation of deviations in real income per capita $(y)^{10}$ :

$$
\operatorname{IncomeDis}_{t}^{k} \equiv \operatorname{std}_{j}\left(\bar{y}_{j}^{k} \mid k\right)
$$

where $\bar{y}_{j}^{k}=\log y_{j}^{k}-\frac{1}{n} \sum_{j=1}^{n} \log y_{j}^{k}$. Similarly, dispersion in value-added tax rates, denoted $\operatorname{VatDis}_{t}^{k}$, is measured by the standard deviation of deviations in VAT rates:

\footnotetext{
10 Real income differences are considered in light of the firm link between price and income levels projected in the context of the Harrod-Balassa-Samuelson hypothesis and the pricing-to-market. Moreover, real per capita income may induce retail price differences through the channel of local costs, such as distribution costs and rents. See Atkeson and Burstein (2008) and Alessandiria and Kaboski (2011) for the mechanisms wherein real income differences affect price dispersion.
} 


$$
\operatorname{VatDis}_{t}^{k} \equiv \operatorname{std}_{j}\left(\overline{\operatorname{VAT}}_{j}^{k} \mid k\right)
$$

where $\overline{V A T}_{j}^{k}=\log V A T_{j}^{k}-\frac{1}{n} \sum_{j=1}^{n} \log V A T_{j}^{k}$. Note that deviations in real income and VAT rates are constructed in the same manner as the price deviation by transforming the data into deviations from the geometric average. Note also that the oil price is common to both international and intra-national samples, while dispersions in real income and VAT rates are group-specific. We estimate Eq. (2) using a panel-pooled OLS estimator without year-fixed effects due to multicollinearity between time-varying regressors and the year dummies. ${ }^{11}$

The inclusion of these variables is motivated by theories underlying international macroeconomics. Dumas (1992), Sercu et al. (1995), and Obstfeld and Rogoff (2000) show that transportation costs generate a band of inaction within which relative prices are bounded. Therefore, one would expect rising oil prices to widen the price wedge and, consequently, increase the limit for time-series fluctuations in the price dispersion. Of special interest in this paper are other time-varying variables that capture structural causes of price dispersion. The income dispersion is intended to reflect consumer purchasing behavior. Alessandria and Kaboski (2011) show that consumers in low-income countries are more price elastic than consumers in high-income countries. This enables firms to vary their markups across markets, and the resulting pricing-to-market will lead to larger price dispersion. As a result, a rising income dispersion is expected to make price more dispersed in the time dimension. VAT rates are directly related to the retail price level of a country and, thus, rising dispersion in VAT rates

\footnotetext{
11 Since we run the regression separately for each country-grouping, we do not consider group-specific effects. In Section 4, we report coefficients on year dummies with time-varying regressors excluded.
} 
will lead prices to be more dispered over time. Since price dispersion is expected to increase over time in the oil price, income dispersion, and VAT dispersion, the coefficients on these regressors are predicted to be positive $\left(\alpha_{1}^{k}>0, \alpha_{2}^{k}>0, \alpha_{3}^{k}>0\right)$.

The interaction terms capture the idea that the explanatory power of the tradeability must increase for goods requiring a high share of traded inputs (i.e., low share of non-traded inputs). In our analysis, we classify goods into three types in terms of tradeability-perishables, nonperishables, and services. Non-perishable goods have lower arbitrage costs than perishable goods because the latter are more easily spoiled within a short period of time and, hence, markets are more segmented by physical proximity. In contrast, consumers of services are not likely to arbitrage the price differentials away. The coefficient $\alpha_{4}\left(\alpha_{5}\right)$ tells us, for a given share of traded inputs, how much the mean price dispersion of non-perishables (perishables) differs from the mean price dispersion of services. ${ }^{12}$ Since prices of non-perishable goods are expected to be less dispersed relative to perishable goods, we expect $\alpha_{4}^{k}<\alpha_{5}^{k}<0$.

\section{Results}

Before exploring the role of time-varying factors, we begin by estimating Eq. (2) assuming year-fixed effects with the time-varying factors excluded:

$$
\operatorname{PriceDis}_{i, t}^{k}=\beta_{0}^{k}++\beta_{1}^{k} \theta_{i} D_{i}^{N P}+\beta_{2}^{k} \theta_{i} D_{i}^{P}+\sum_{t=1995}^{2013} \gamma_{t} Y_{e a r_{t}}+\epsilon_{i, t}^{k}
$$

where Year $_{t}$ denotes the year dummy variables. The coefficients for the year dummies with $95 \%$ 
confidence bands are plotted in Fig. 4. It is evident that time patterns in price dispersion differ significantly across country groupings, indicating that time-invariant variables such as goods characteristics and geographic factors alone cannot explain this feature of price dispersion which varies over time in a heterogeneous manner across groupings.

Panel A of Table 2 summarizes our benchmark regression results for world and US cities with a full set of time-varying explanatory variables included. Focusing on the coefficients for time-varying factors, a striking difference is seen in both magnitude and significance across groupings. In the world case, $\alpha_{2}$ and $\alpha_{3}$ are of the hypothesized sign and highly significant, while we are not able to reject the null hypothesis for $\alpha_{1}$. The positive estimate of $\alpha_{2}^{\text {World }}$ is consistent with the sign prediction of the theory, relating rising income dispersion to a rising tendency in international price dispersion. That is, rising income dispersion enables firms to more easily identify different market segments, resulting in more variability in markups over time and, therefore, a rise in price dispersion. The positive estimate of $\alpha_{3}^{\text {World }}$ implies that price dispersion drops over time as VAT system regulations become harmonized.

Contrary to the world case, time variation in US price dispersion appears to occur regardless of the income dispersion. Compared to the World sample, we cannot reject the hypothesis that $\alpha_{2}^{U S}$ is equal to zero. Instead, oil prices appear to play a significantly important role in generating fluctuations in price dispersion. A possible explanation is that, in a highly integrated region such as the US market, firms' ability to price-to-market is relatively hampered and, thus, transportation costs play a greater role in driving time variation in price deviations. Geographical integration and proximity are much greater for cities in the US than those demonstrated across the world. In light of this aspect, the significance of the oil prices in the US case reflects the fact

\footnotetext{
${ }^{12}$ Here, we consider services as the base category.
} 
that most of the goods in the US are delivered by trucks. Its insignificance in the world sample, on the other hand, is evidence that alternative modes of transport prevail in other parts of the world.

The VAT dispersion turns out to matter in both world and US cases, suggesting that the scope for VAT harmonization contributes to price dispersion variation regardless of the border effects.

The combination of world and US cases suggests the trade-off that exists for the role of timevarying factors as contributors to price dispersion variation. The role of the income dispersion in accounting for price dispersion variation is more pronounced as we move beyond an economic geography, while transportation costs matter relatively more if we move to the interior of this geography. The VAT dispersion is the only time-varying factor that commonly affects price dispersion variation for geographic dimensions. Studying different dimensional city pairs, as is done in our analysis, helps in this regard by identifying this trade-off.

Panel B of Table 3 reports the results of regressing the residuals of the specification (2) on the year dummies. Compared to Fig. 4, the coefficients for the year dummies are mostly much smaller and statistically not significant, indicating that our time-varying factors capture most of the time variation in price dispersion.

To visualize how individual time-varying factors contribute to price dispersion variation over time, in Fig. 5 and Fig. 6 we plot the average price dispersion together with the price dispersion adjusted for the effects of oil prices, income dispersion, and VAT dispersion where adjustment is constructed as follows: ${ }^{13}$ 


$$
\begin{gathered}
{\text { Oil }- \text { adjusted }_{t}=}=\frac{1}{300} \sum_{i=1}^{300} \text { PriceDis }_{i, t}^{k}-\alpha_{1}^{k}\left(\ln \left(\text { Oil }_{t}\right)-\frac{1}{20} \sum_{t=1994}^{2013} \ln \left(\text { Oil }_{t}\right)\right) \\
{\text { Income }- \text { adjusted }_{t}}=\frac{1}{300} \sum_{i=1}^{300} \text { PriceDis }_{i, t}^{k}-\alpha_{2}^{k}\left(\text { IncomeDis }_{t}^{k}-\frac{1}{20} \sum_{t=1994}^{2013} \text { IncomeDis }_{t}^{k}\right) \\
\text { VAT }- \text { adjusted }_{t}=\frac{1}{300} \sum_{i=1}^{300} \text { PriceDis }_{i, t}^{k}-\alpha_{3}^{k}\left(\text { VatDis }_{t}^{k}-\frac{1}{20} \sum_{t=1994}^{2013} \text { VatDis }_{t}^{k}\right)
\end{gathered}
$$

The figures show that, once the effect of income dispersion is subtracted, the remaining fluctuations in world price dispersion differ remarkably from actually observed price dispersion, indicative of the crucial role of income dispersion. However, in the case of the US, price dispersion adjusted for income dispersion still moves closely with observed price dispersion, while VAT dispersion and, in particular, oil prices explain a significant portion of price dispersion fluctuations. Hence, we see that the role of time-varying factors in accounting for price dispersion variation is reversed in the context of geographical integration. Structural causes, such as income dispersion, tend to matter more across locations that are farther apart and more segmented, while transportation cost is a main driver of time variatin within an integrated region.

While the focus of this paper is on the time dimension of price dispersion, the coefficients for the goods characteristics also provide meaningful implications. Consistent with conventional wisdom, given the share of traded inputs, prices of non-perishable and perishable goods are less dispersed than prices of service goods and the coefficient for non-perishables is significantly larger than that of perishables in the international case. Interestingly, we see the opposite within the US-price dispersion of perishables is comparable to that of non-perishable goods. This means that, in a highly integrated market, it is possible that the nature of perishability makes

\footnotetext{
${ }^{13}$ We follow Bergin and Glick (2007) in constructing the adjusted values.
} 
arbitrage more urgent and can, thus, lead to stronger arbitrage, resulting in less price dispersion of perishables in the US.

Negative coefficients for $\alpha_{4}$ and $\alpha_{5}$ also imply that prices of retail goods with a higher share of traded inputs are less dispersed than goods with complementary features. This supports the view that price differentials of traded inputs contained in retail goods tend to be arbitraged away, suggesting that no individual item actually satisfies a strict dichotomy of tradeable and non-tradeable goods due to the presence of intermediate inputs.

To examine the sensitivity of the main results to the country sample, we estimate Eq. (2) on the subsamples of all the international cities. The estimation results for OECD and EU member countries are reported in Table 3. We see that the main results are preserved, except that oil prices also matter for the EU case. Recognizing the fact that geographical integration and proximity are much greater for cities within the EU than those demonstrated across OECD countries, we view this result as confirming our finding that structural causes have larger effects on price dispersion variation when the locations are more segmented with transportation costs playing a relatively more significant role in an integrated region.

\section{Conclusion}

The empirical analysis conducted in this paper attempts to shed light on sources of price dispersion variation in the time dimension. The first source of variation is oil prices associated with transportation costs; the second is income dispersion that capture a firm's opportunity to price-to-market; and the third is VAT dispersion directly related to consumption tax regulations. We include these time-varying factors in the regression based on the recognition that standard 
time-invariant gravity factors have difficulty explaining why price dispersion exhibits different time patterns across country groupings. The theories underlying international macroeconomics predict prices to be dispersed more over time with a rise in oil prices, income dispersion, and VAT dispersion. We examine whether these predictions are confirmed using the retail prices of 300 individual goods and services across cities during 1994 to 2013. An important insight arising from our analysis is that the main driver of time variation is reversed across two dimensions of geography. While helpful in accounting for the time variation of price dispersion in the world and OECD cases, income dispersion does not explain a significant portion of the price dispersion variation within the US and EU. On the other hand, the role of oil prices does matter within the US and EU, whereas world and OECD price dispersion does not significantly fluctuate in response to changes in oil prices. This implies that structural causes, such as income dispersion, tend to matter more across locations that are farther apart and more segmented, while transportation cost is a main driver of time variatin within an integrated region. The VAT dispersion appears to affect price dispersion variation for both geographic dimensions. The tradeoff that exists for the role time-varying factors play as contributors to price dispersion variation must, therefore, arise from the interactions between economic geography and time-varying market segmentation. Studying different dimensional city pairs, as is done in this paper, helps in this regard by identifying this trade-off.

We view our time-varying factors as conservative measures of transportation costs and structural causes. We hope to provide more concrete evidence on this dimension in future work. As emphasized by Kole et al. (2006), structural causes, such as pricing-to-market and consumption tax regulations, may also hinge on an individual's expectations about the duration of crisis. It would be interesting, therefore, to incorporate the persistence of crises in our analysis 
of price dispersion variation.

\section{References}

Alessandria, G., Kaboski, J. 2011. Pricing-to-market and the failure of absolute PPP. American Economic Journal: Macroeconomics 3(1), 91-127.

Andrade, P., Zachariadis, M., 2016. Global versus local shocks in micro price dynamics. Journal of International Economics 98, 78-92.

Atkeson, A., Burstein, A., 2008. Pricing-to-market, trade costs, and international relative prices. American Economic Review 98(5), 1998-2031.

Bergin, P., Glick, R., 2007. Global price dispersion: Are prices converging or diverging? Journal of International Money and Finance 26, 703-729.

Burstein, A., Jaimovich, N., 2012. Understanding movements in aggregate and product-level real exchange rates, UCLA working paper.

Crucini, M., Shintani, M., Tsuruga, T., 2010.Accounting for persistence and volatility of goodlevel real exchange rates: The role of sticky information. Journal of International Economics $81,48-60$.

Crucini, M., Shintani, M., 2008. Persistence in law of one price deviations: Evidence from micro-data. Journal of monetary Economics, 55, 629-644.

Crucini, M., Telmer, C., Zachariadis, M., 2005. Understanding European real exchange rates. American Economic Review 95(3), 724-738.

Cuddington, J., Liang, H., 2000. Purchasing power parity over two centuries? Journal of International Money and Finance 19, 753-757.

Dumas, B., 1992, "Dynamic equilibrium and the real exchange rate in a spatially separated world," Review of Financial Studies 5, 153-180.

Gopinath, G., Gourinchas, P., Hsieh C., 2011. International prices, costs and markup differences. American Economic Review 101(6), 2450-2486.

Glushenkova, M., Zachariadis, M., 2016. Understanding post-Euro law-of-one price deviations. Journal of Money Credit and Banking 48, 1073-1111.

Klenow, P., Malin, B., 2010. Microeconomic evidence of price-setting. NBER working paper 15826. 
Kole, E., Koedijk, K., Verbeek., 2006. Portfolio implications of systematic crises. Journal of banking and finance 30, 2347-2369.

Lothian, J., Taylor, M., 2008. Real exchange rates over the past two centuries: how important is the Harrod-Balassa-Samuelson effect? Economic Journal, 118, 1742-1763.

Lothian, J., Taylor, M., 2000. Purchasing power parity over two centuries: strengthening the case for real exchange rate stability: a reply to Cuddington and Liang. Journal of International Money and Finance 19, 759-764.

Lothian, J., Taylor, M., 1996. Real exchange rate behavior: the recent float from the perspective of the past two centuries. Journal of Political Economy 104, 488-509.

Murray C., Papell, D., 2002. The purchasing power parity persistence paradigm. Journal of International Economy 56, 1-19.

Obstfeld, M., Rogoff, K., 2000. The six major puzzles in international macroeconomics: is there a common cause? in Ben S. Bernanke and Kenneth Rogoff, eds., NBER Macroeconomics Annual 2000, Cambridge, MA: The MIT Press.

Parsley, D., Wei, S., 2008. In search of a euro effect: Big lessons from a big mac meal? Journal of International Money and finance 27(2), 260-276.

Rogers, J., 2007. Monetary union, price level convergence, and inflation: How close is Europe to the USA? Journal of Monetary economics 54, 785-796.

Sarno, L., Taylor, M., Chowdhury., 2004. Nonlinear dynamics in deviations from the law of one price: a broad-based empirical study. Journal of International Money and Finance 23, 1-25.

Sercu, P., Uppal, R., Van Hulle, C., 1995. The exchange rate in the presence of transaction costs: implications for tests of purchasing power parity. Journal of Finance 50, 1309-1319. 
Fig. 1. Kernel density estimates of LOP deviations

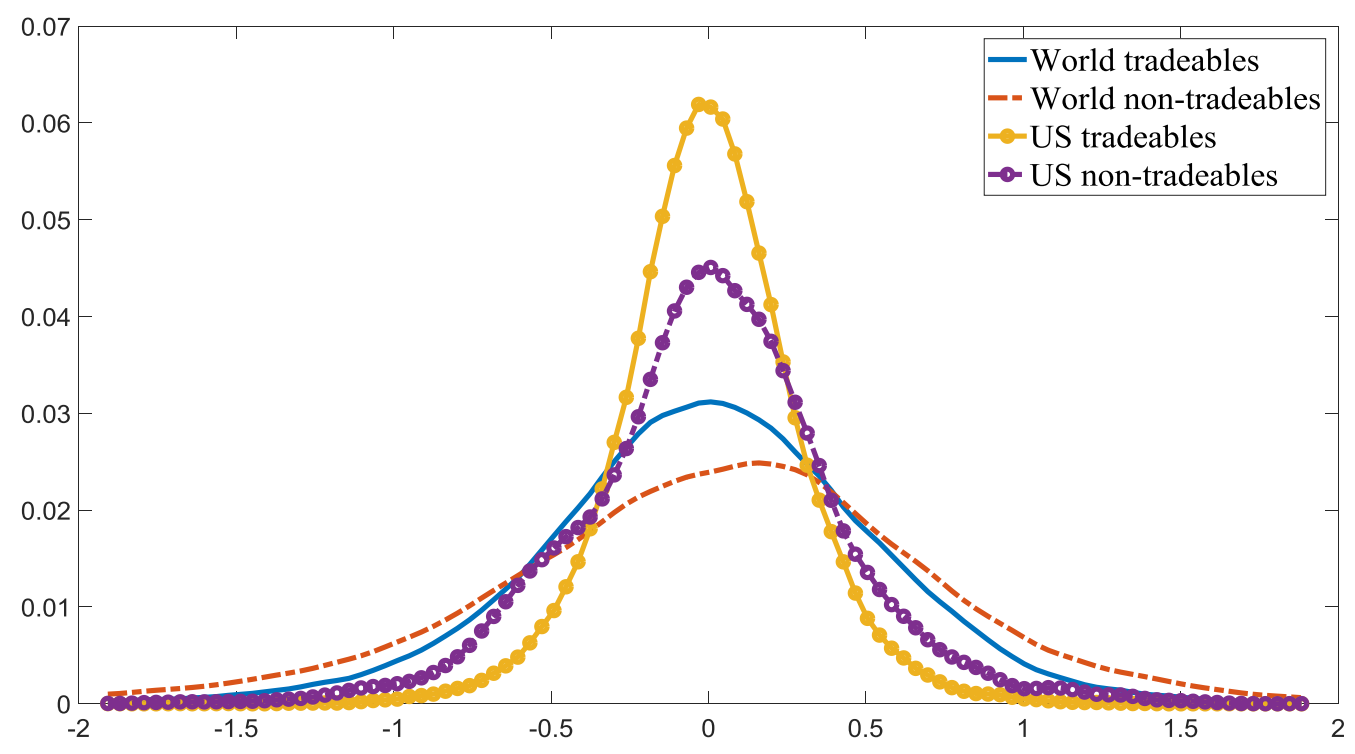

Note: The densities describe cross-sectional variation in $\bar{P}_{i j}^{k}$ across goods and locations, pooling all years, where $\bar{P}_{i j}^{k}$ is computed as $\bar{P}_{i j}^{k}=\log P_{i j}^{k}-\frac{1}{n} \sum_{j=1}^{n} \log P_{i j}^{k}$ 
Fig. 2. Trends of price dispersion and time-varying factors: World

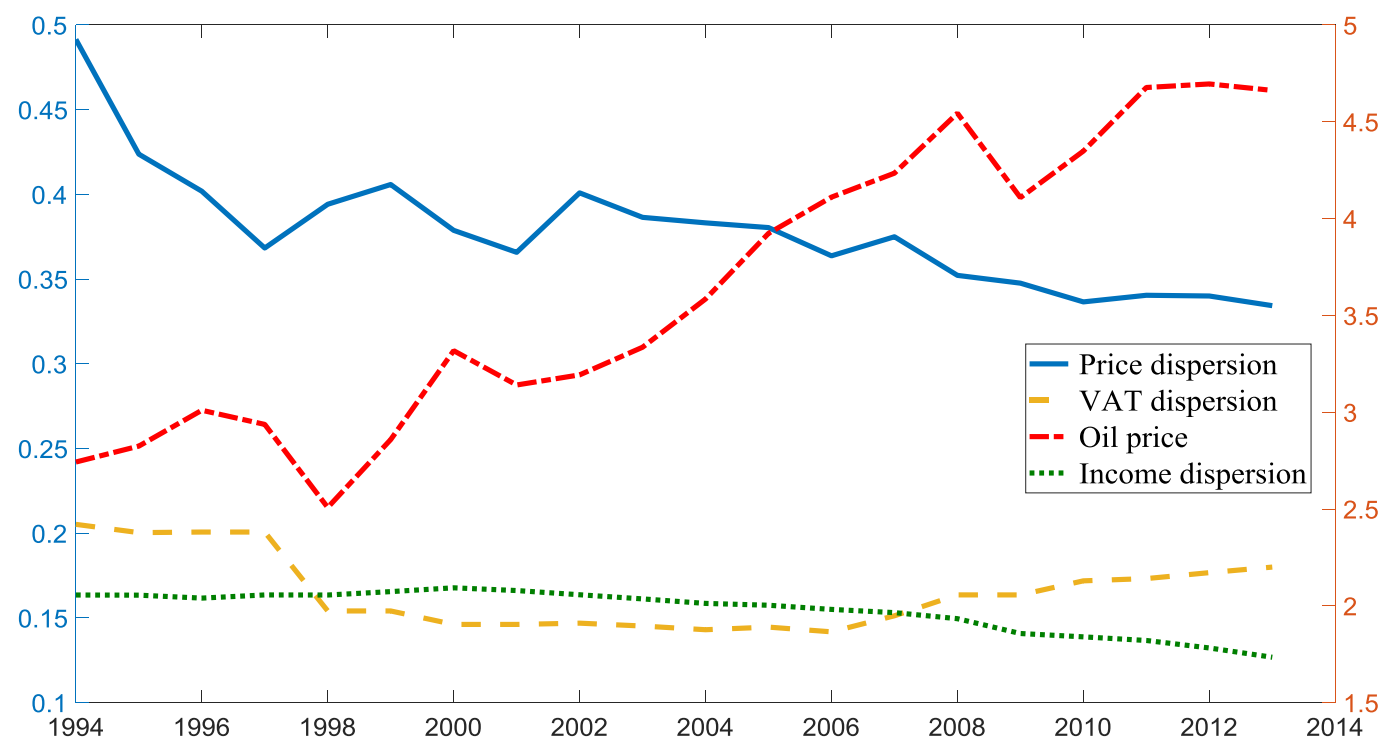

Note: Each line represents the time series of the measure of price dispersion, income dispersion, VAT dispersion, and oil prices, averaged over all goods on a year-by-year basis over the period 1994-2013. 
Fig. 3. Trends of price dispersion and time-varying factors: US

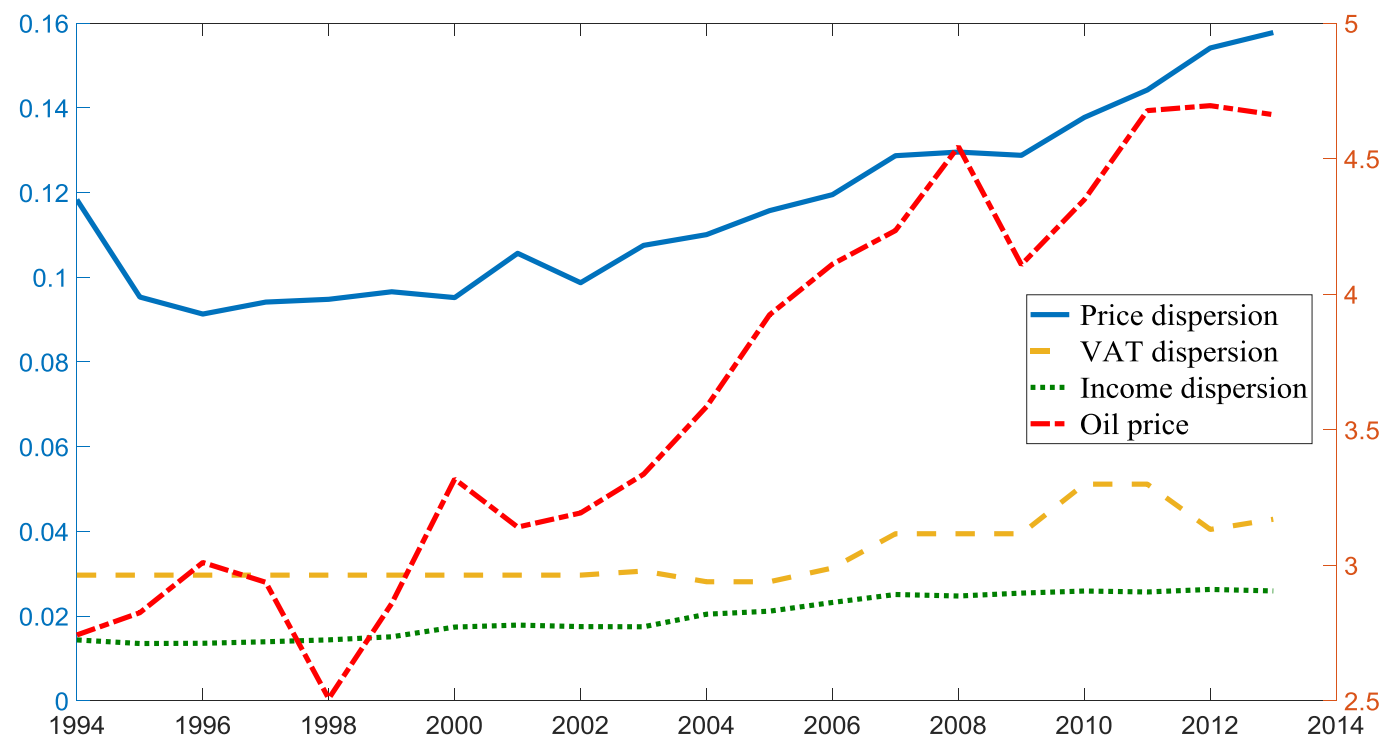

Note: Each line represents the time series of the measure of price dispersion, income dispersion, VAT dispersion, and oil prices, averaged over all goods on a year-by-year basis over the period 1994-2013. 
Fig. 4. Year fixed effect coefficients
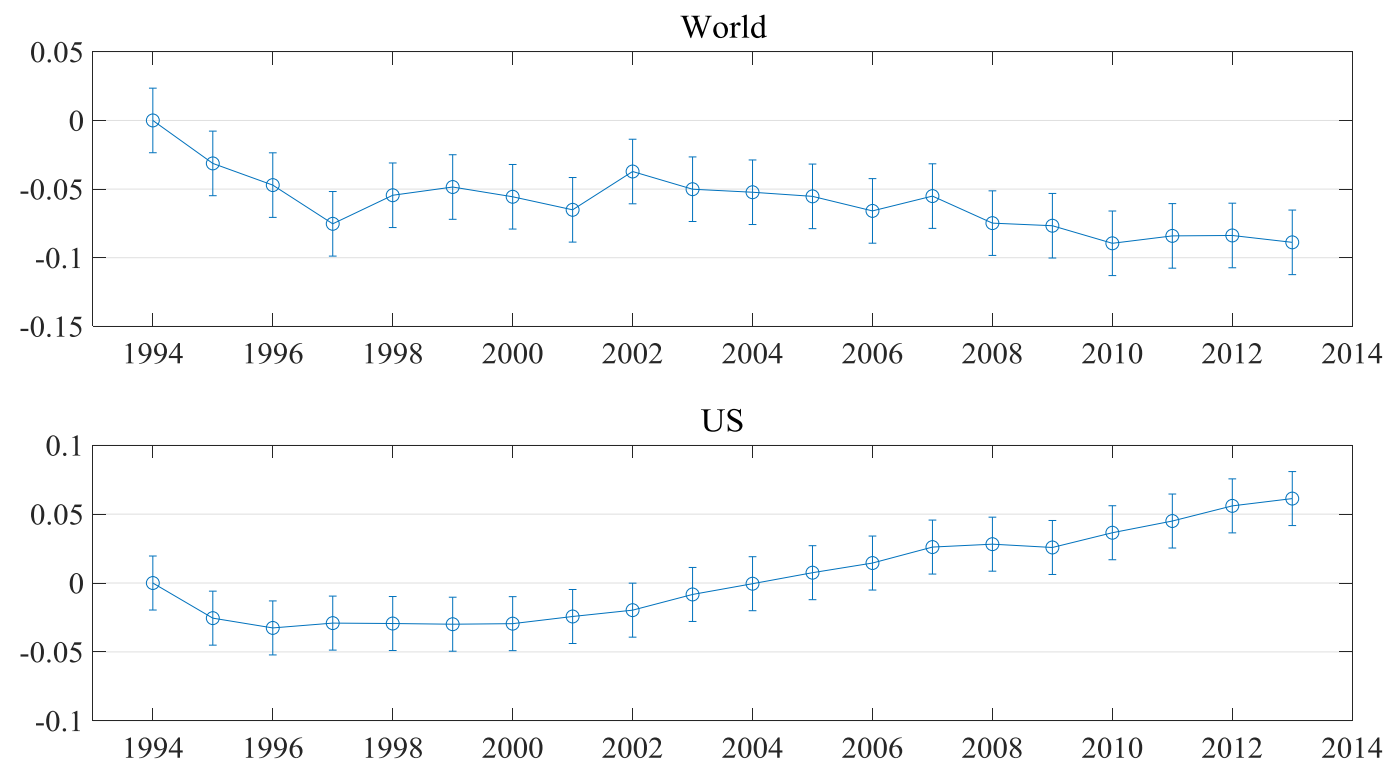

Note: Each line represents the coefficients for the year dummies with $95 \%$ confidence bands, with the time-varying factors excluded in the regression. 
Fig. 5. Price dispersion adjusted for effects of time-varying factors: World

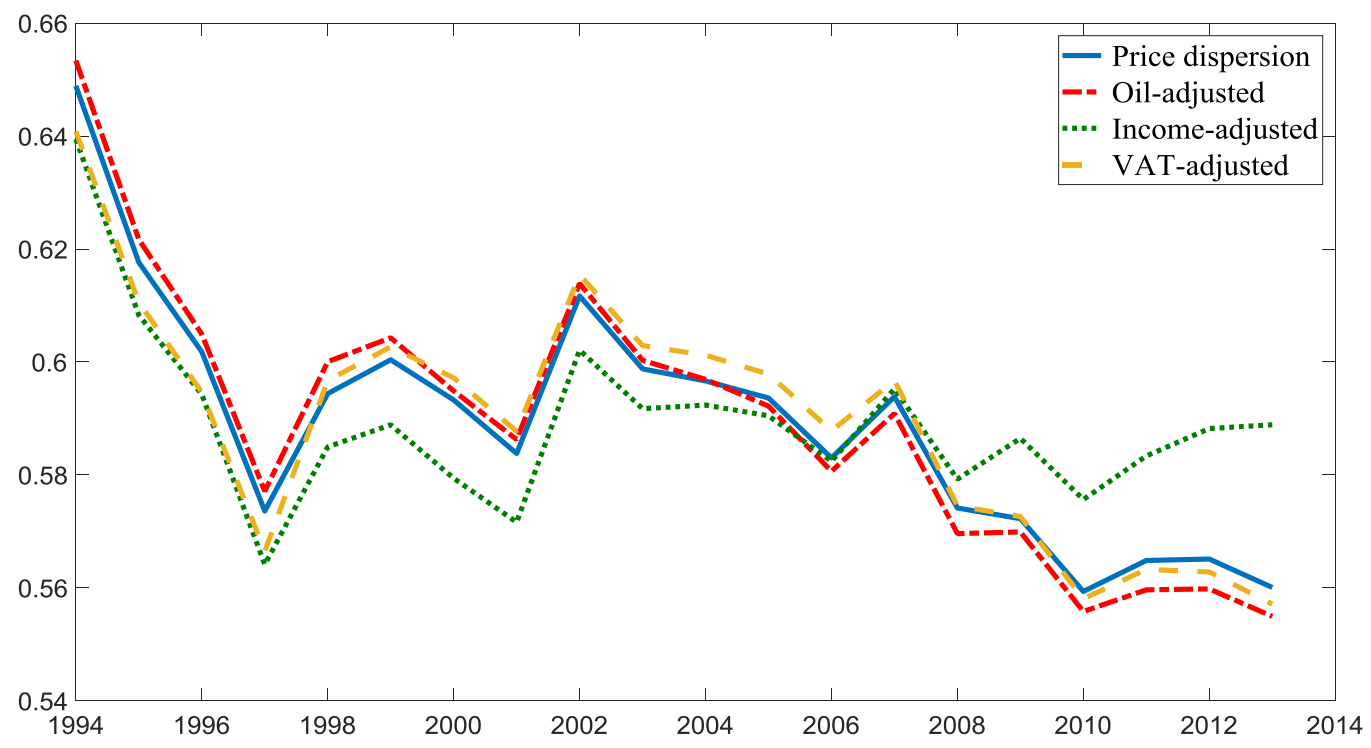

Note: Each line represents the average price dispersion for the World sample, unadjusted and adjusted for oil prices, income differences, and VAT differences. 
Fig. 6. Price dispersion adjusted for effects of time-varying factors: US

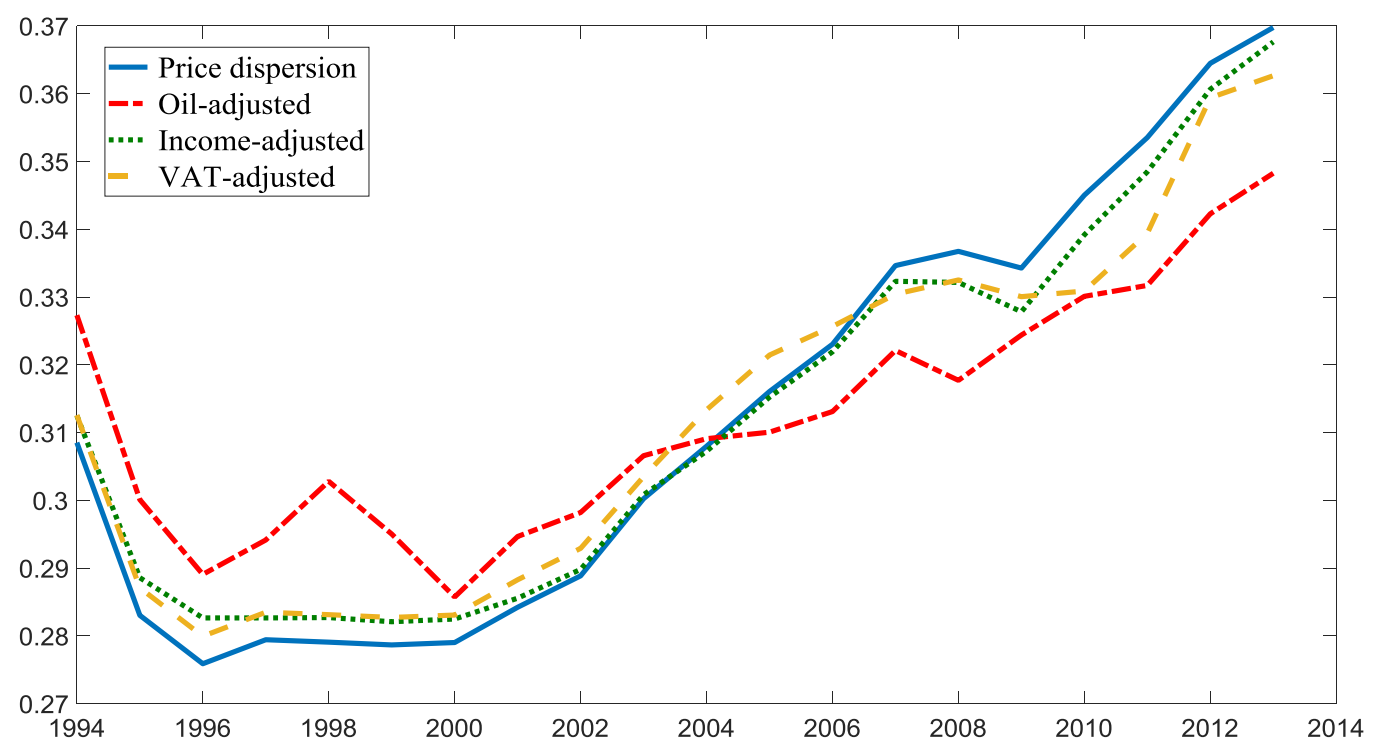

Note: Each line represents the average price dispersion for the US sample, unadjusted and adjusted for oil prices, income differences, and VAT differences. 
Fig. 7. Price dispersion adjusted for effects of time-varying factors: OECD

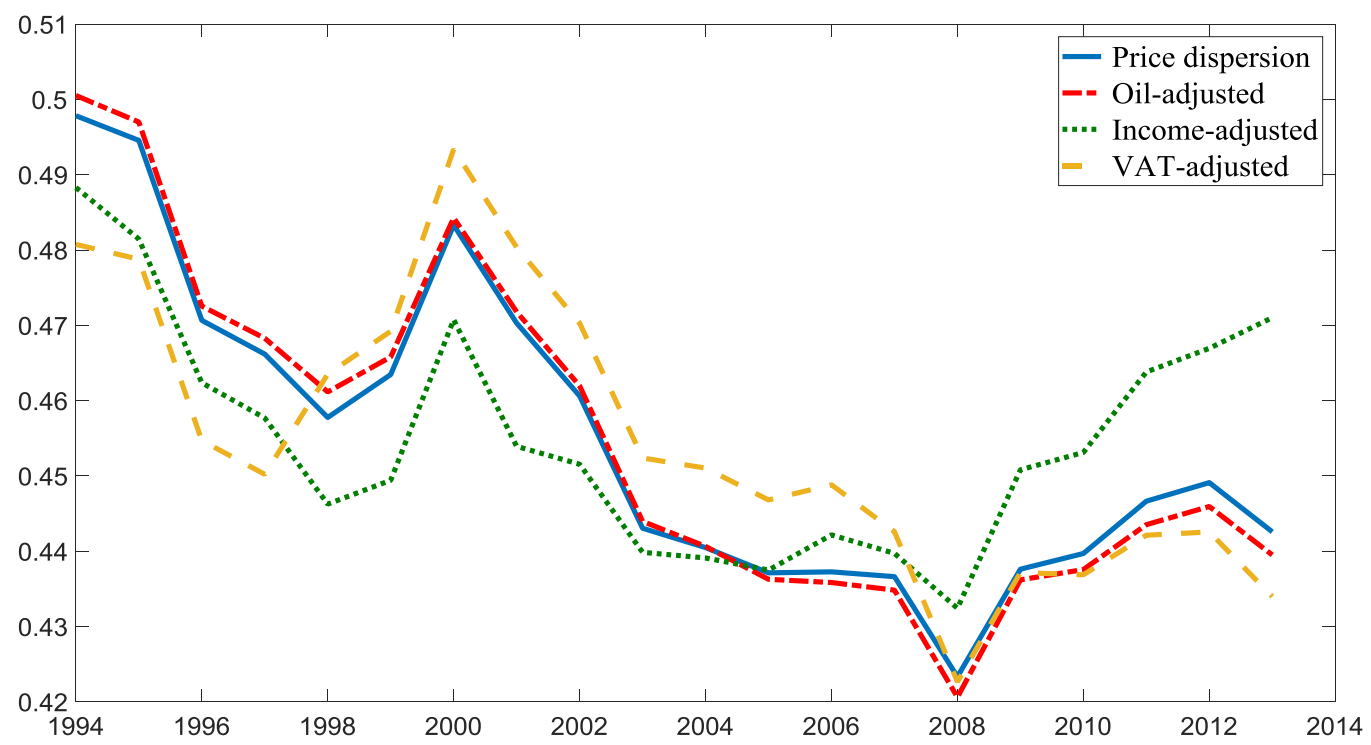

Note: Each line represents the average price dispersion for the OECD sample, unadjusted and adjusted for oil prices, income differences, and VAT differences. 
Fig. 8. Price dispersion adjusted for effects of time-varying factors: $\mathrm{EU}$

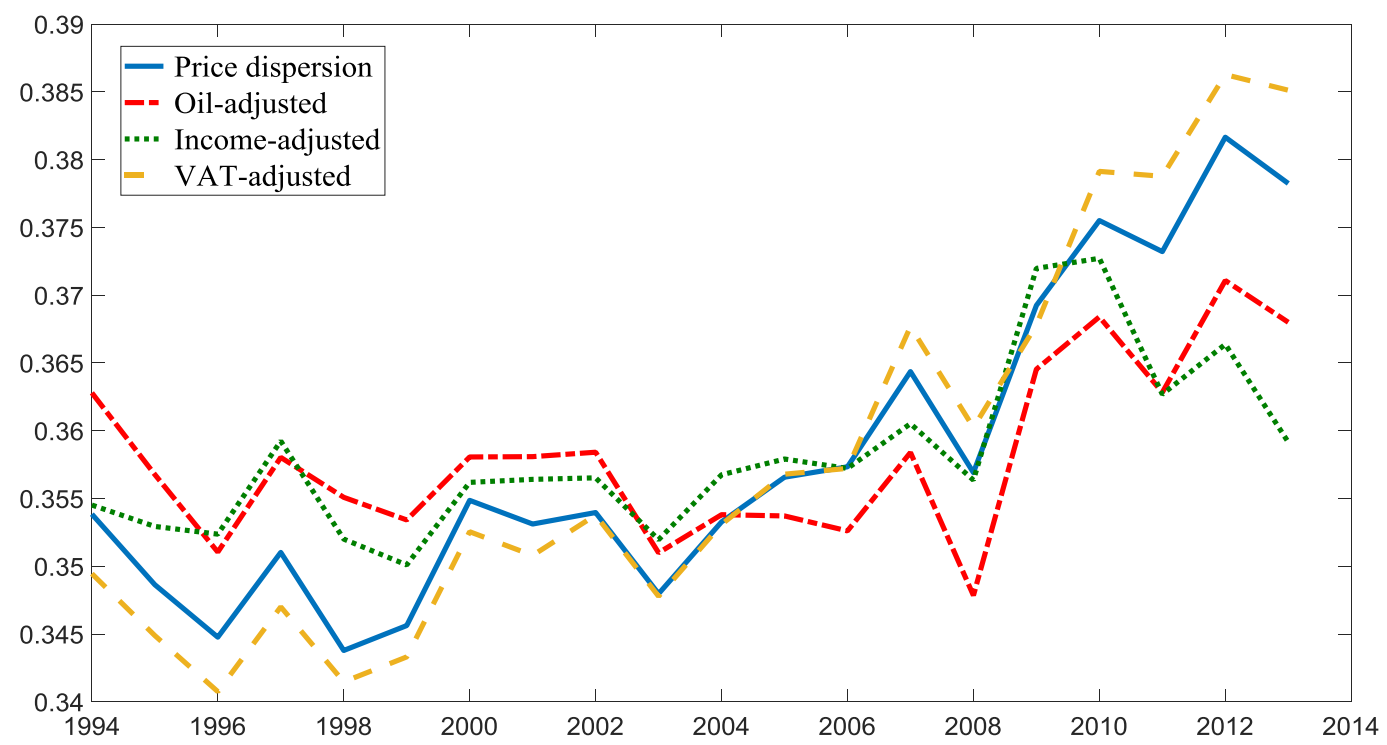

Note: Each line represents the average price dispersion for the EU sample, unadjusted and adjusted for oil prices, income differences, and VAT differences. 
Table 1. List of cities

\begin{tabular}{|c|c|c|}
\hline World cities & & U.S. cities \\
\hline Abidjan, Cote d'Ivoire (277) & Jakarta, Indonesia (283) & Atlanta (284) \\
\hline Abu Dhabi, UAE (293) & Johannesburg, South Africa (294) & Boston, (299) \\
\hline Adelaide, Australia (299)* & Karachi, Pakistan (260) & Chicago (291) \\
\hline Al Khobar, Saudi Arabia (258) & Kuala Lumpur, Malaysia (288) & Cleveland (292) \\
\hline Amman, Jordan (289) & Kuwait, Kuwait (238) & Detroit (285) \\
\hline Amsterdam, Netherlands $(299) * * *$ & Lagos, Nigeria (270) & Honolulu (283) \\
\hline Asuncion, Paraguay (285) & Lima, Peru (288) & Houston (290) \\
\hline Athens, Greece $(294)^{*}, * *$ & Lisbon, Portugal (298)*,** & Lexington (271) \\
\hline Atlanta, USA (298)* & London, U.K. (300)*,** & Los Angeles (291) \\
\hline Auckland, New Zealand (286)* & Luxembourg, Luxembourg (293)*,** & Miami (271) \\
\hline Bahrain, Bahrain. (263) & Lyon, France $(297)^{*}, * *$ & Minneapolis (279) \\
\hline Bangkok, Thailand (295) & Manila, Philippines (278) & New York (297) \\
\hline Barcelona, Spain $(300) * * *$ & Mexico city, Mexico (284)* & Pittsburgh (284) \\
\hline Beijing, China (298) & Milan, Italy $(300)^{*}, * *$ & San Francisco (298) \\
\hline Belgrade, Serbia (280) & Montevideo, Uruguay (289) & Seattle (284) \\
\hline Berlin, Germany $(300) * * *$ & Moscow, Russia (293) & Washington DC (291) \\
\hline Bogota, Columbia (282) & Mumbai, India (276) & \\
\hline Brussels, Belgium (295)*,** & Nairobi, Kenya (285) & \\
\hline Bucharest, Romania (290) & Osaka, Japan (290)* & \\
\hline Budapest, Hungary (297)* & Oslo, Norway $(280)^{*}$ & \\
\hline Buenos Aires, Argentina (296) & Panama city, Panama (286) & \\
\hline Cairo, Egypt (272) & Port Moresby, Papua New Guinea & \\
\hline Calgary, Canada $(297)^{*}$ & $(232)$ & \\
\hline Caracas, Venezuela (277) & Prague, Czech Republic (297)* & \\
\hline Casablanca, Morocco (286) & Quito, Ecuador (288) & \\
\hline Colombo, Sri Lanka (258) & Rio De Janeiro, Brazil (297) & \\
\hline Copenhagen, Denmark $(293)^{*}, * *$ & San Jose, Costa Rica (279) & \\
\hline Dakar, Senegal (279) & Santiago, Chile (286) & \\
\hline Douala, Cameroon (253) & Seoul, South Korea $(286)^{*}$ & \\
\hline Dublin, Ireland $(290)^{*}, * *$ & Singapore, Singapore (299) & \\
\hline Geneva, Switzerland (297)* & Stockholm, Sweden $(277)^{*}, * *$ & \\
\hline Guatemala city, Guatemala (287) & Taipei, Taiwan (293) & \\
\hline Hanoi, Vietnam (281) & Tehran, Iran (242) & \\
\hline Harare, Zimbabwe (258) & Tel Aviv, Israel (279) & \\
\hline Helsinki, Finland (289)*** & Tripoli, Libya (180) & \\
\hline Hong Kong SAR (296) & Tunis, Tunisia (258) & \\
\hline \multirow[t]{2}{*}{ Istanbul, Turkey $(292)^{*}$} & Vienna, Austria $(298) *, * *$ & \\
\hline & Warsaw, Poland (278)* & \\
\hline
\end{tabular}

Note: The number of goods from a particular city used in the estimation is in parentheses. ${ }^{*}$ and ${ }^{* *}$ indicate cities in the OECD and EU, respectively. 
Table 2. Regression results

\begin{tabular}{|c|c|c|}
\hline & World & United States \\
\hline \multicolumn{3}{|l|}{ Panel A: Coefficient estimates } \\
\hline \multirow[t]{2}{*}{ Log oil price } & 0.005 & $0.021 * * *$ \\
\hline & $(0.007)$ & $(0.009)$ \\
\hline \multirow[t]{2}{*}{ Income dispersion } & $0.119 * * *$ & 0.703 \\
\hline & $(0.044)$ & $(0.610)$ \\
\hline \multirow[t]{2}{*}{ VAT dispersion } & $0.203^{*}$ & $0.847 * * *$ \\
\hline & $(0.109)$ & $(0.359)$ \\
\hline \multirow[t]{2}{*}{ Traded inputs $\mathrm{X}$ nonperishables } & $-0.314 * * *$ & $-0.169 * * *$ \\
\hline & $(0.006)$ & $(0.005)$ \\
\hline \multirow{2}{*}{ Traded inputs $\mathrm{x}$ perishables } & $-0.219 * * *$ & $-0.162 * * *$ \\
\hline & $(0.007)$ & $(0.006)$ \\
\hline Year fixed effects & No & No \\
\hline Adjusted $R$-squared & 0.417 & 0.309 \\
\hline \multirow{2}{*}{\multicolumn{3}{|c|}{$\begin{array}{l}\text { Panel B. Coefficients of regressing residuals } \\
\text { in Eq. (1) on year dummies: }\end{array}$}} \\
\hline & & \\
\hline 1995 & 0.002 & 0.007 \\
\hline 1996 & 0.008 & 0.004 \\
\hline 1997 & -0.006 & -0.007 \\
\hline 1998 & $-0.036 * * *$ & -0.003 \\
\hline 1999 & -0.008 & 0.005 \\
\hline 2000 & -0.002 & -0.004 \\
\hline 2001 & -0.008 & $-0.018 * *$ \\
\hline 2002 & $-0.016^{*}$ & -0.009 \\
\hline 2003 & 0.014 & -0.006 \\
\hline 2004 & 0.005 & 0.002 \\
\hline 2005 & 0.007 & 0.001 \\
\hline 2006 & 0.007 & 0.001 \\
\hline 2007 & 0.001 & -0.002 \\
\hline 2008 & 0.012 & -0.004 \\
\hline 2009 & -0.005 & -0.007 \\
\hline 2010 & -0.001 & -0.002 \\
\hline 2011 & -0.011 & -0.007 \\
\hline 2012 & -0.002 & -0.005 \\
\hline 2013 & 0.002 & $0.013 *$ \\
\hline
\end{tabular}

Note: Panel A reports the coefficients estimated from the benchmark regression specification (1). Panel B reports the results of regressing the residuals of the benchmark regression (1) on the year dummies. Numbers in parentheses are standard errors. $* * *, * *$, and $*$, respectively, indicate significance at the $1 \%, 5 \%$, and $10 \%$ levels. 
Table 3. Regression results for OECD and EU

\begin{tabular}{lcc}
\hline \hline & OECD & EU \\
\hline Log oil price & 0.003 & $0.010^{* *}$ \\
& $(0.006)$ & $(0.005)$ \\
Income dispersion & $0.551^{* * *}$ & $0.639^{* * *}$ \\
& $(0.169)$ & $(0.262)$ \\
VAT dispersion & $0.425^{* * *}$ & $1.078^{*}$ \\
& $(0.069)$ & $(0.610)$ \\
Traded inputs x nonperishables & $-0.182^{* * *}$ & $-0.163^{* * *}$ \\
& $(0.005)$ & $(0.005)$ \\
Traded inputs x perishables & $-0.076^{* * *}$ & $-0.141^{* * *}$ \\
& $(0.005)$ & $(0.005)$ \\
Year fixed effects & No & No \\
Adjusted $R$-squared & 0.327 & 0.305 \\
\hline \hline
\end{tabular}

Note Numbers in parentheses are standard errors. $* * *, * *$, and $*$, respectively, indicate significance at the $1 \%, 5 \%$, and $10 \%$ levels. 